\title{
Effect of Hydration Status on Cerebral Blood Flow and Cerebrospinal Fluid Lactic Acidosis in Rabbits with Experimental Meningitis
}

\author{
Jay H. Tureen, ${ }^{*}$ Martin G. Täuber, ${ }^{\star}$ and Merle A. Sande ${ }^{\star}$ \\ Departments of ${ }^{*}$ Pediatrics and ${ }^{\ddagger}$ Medicine, University of California, San Francisco, \\ and San Francisco General Hospital, San Francisco, California 94110
}

\begin{abstract}
The effects of hydration status on cerebral blood flow (CBF) and development of cerebrospinal fluid (CSF) lactic acidosis were evaluated in rabbits with experimental pneumococcal meningitis. As loss of cerebrovascular autoregulation has been previously demonstrated in this model, we reasoned that compromise of intravascular volume might severely affect cerebral perfusion. Furthermore, as acute exacerbation of the inflammatory response in the subarachnoid space has been observed after antibiotic therapy, animals were studied not only while meningitis evolved, but also 4-6 h after treatment with antibiotics to determine whether there would also be an effect on CBF. To produce different levels of hydration, animals were given either $50 \mathrm{ml} / \mathrm{kg}$ per $24 \mathrm{~h}$ of normal saline ("low fluid") or $150 \mathrm{ml} / \mathrm{kg} 24 \mathrm{~h}$ ("high fluid"). After $16 \mathrm{~h}$ of infection, rabbits that were given the lower fluid regimen had lower mean arterial blood pressure (MABP), lower CBF, and higher CSF lactate compared with animals that received the higher fluid regimen. In the first 4-6 $\mathrm{h}$ after antibiotic administration, low fluid rabbits had a significant decrease in MABP and CBF compared with, and a significantly greater increase in CSF lactate concentration than, high fluid rabbits. This study suggests that intravascular volume status may be a critical variable in determining CBF and therefore the degree of cerebral ischemia in meningitis. (J. Clin. Invest. 1992. 89:947-953.) Key words: cerebral blood flow $\bullet$ cerebrospinal fluid lactate $\cdot$ experimental meningitis
\end{abstract}

\section{Introduction}

It has been demonstrated in experimental $(1,2)$ and clinical studies $(3,4)$ that cerebral blood flow $(C B F)^{1}$ is reduced in bacterial meningitis, and the clinical studies have shown an association between cerebral ischemia and poor neurological outcome or death. CBF is influenced by a number of factors, including tissue metabolic demand, blood oxygen and carbon

This work was presented in part at the Society for Pediatric Research Meeting, 30 April 1991, Washington, DC.

Address reprint requests to J. H. Tureen, M.D., San Francisco General Hospital, 6-E-9, 1001 Potrero Avenue, San Francisco, CA 94110.

Received for publication 12 March 1991 and in revised form 14 October 1991.

1. Abbreviations used in this paper: CBF, cerebral blood flow; CPP, cerebral perfusion pressure; CSF, cerebrospinal fluid; MABP, mean arterial blood pressure; SIADH, syndrome of inappropriate secretion of antiduretic hormone.

J. Clin. Invest.

(C) The American Society for Clinical Investigation, Inc.

0021-9738/92/03/0947/07 \$2.00

Volume 89, March 1992, 947-953 dioxide concentrations, and cerebral perfusion pressure (CPP). CPP is a critical variable because it may be affected by therapy or systemic events that lead to changes in blood pressure and intracranial pressure and because it is amenable to specific interventions. Clinical data indicate that reduction of CPP below a certain threshold is strongly associated with death or major neurological sequelae in children with intracranial infections $(5,6)$. Since autoregulation of CBF may be impaired during meningitis, this provides a mechanism by which reduction in mean arterial blood pressure (MABP) and thus reduction in CPP can have profound effects on CBF (7). It is currently recommended that children with bacterial meningitis receive less than maintenance intravenous fluids until the syndrome of inappropriate secretion of antidiuretic hormone has been excluded (8), although a recent clinical study has evaluated a more liberal regimen of fluid administration (9). The present study was designed to examine the role of volume status on the cerebrovascular and cerebral metabolic events during meningitis. We studied two groups of animals, the volume statuses of which were determined by different rates of fluid administration to produce either normal hydration status or relative hypovolemia. In addition, since we have recently shown in this model that there may be an acute exacerbation of the inflammatory response in the subarachnoid space after antibiotic administration, leading to increased brain edema (10), we studied the animals both during the developing infection and in the first few hours after treatment with antibiotics to determine whether there is also an acute effect on CBF.

\section{Methods}

Studies were conducted using New Zealand White rabbits $(2.0-2.5 \mathrm{~kg})$. Meningitis was induced by a modification of the method of Dacey and Sande (11). Rabbits were anesthetized with urethane $(2.0 \mathrm{~g} / \mathrm{kg}$ i.v. $)$ for all procedures and received supplemental doses in the first $12 \mathrm{~h}(0.5$ $\mathrm{g} / \mathrm{kg}$ i.v.) to maintain light general anesthesia. Arterial catheters (PE90) were inserted in the right femoral artery and left ventricle. MABP was measured by a physiologic pressure transducer (Gould Statham P-23 XL; Gould Inc., Santa Clara, CA) calibrated before each experiment with a blood pressure manometer and was recorded on a multichannel polygraph (model 5/6H; Gilson Medical Electronics, Inc., Middleton, WI).

Meningitis was induced by direct intracisternal injection of $\sim 1$ $\times 10^{5}$ colony-forming units of Streptococcus pneumoniae, type III, obtained from a clinical isolate. Infection was confirmed by direct plating of spinal fluid on blood agar plates incubated for $24 \mathrm{~h}$ at $37^{\circ} \mathrm{C}$ in room air containing $5 \% \mathrm{CO}_{2}$. Bacterial titer was determined by serial 10 -fold dilution of spinal fluid.

Arterial blood gases were measured at baseline conditions and before CBF measurements, using a clinical blood gas laboratory (ABL model 2; Radiometer Instruments, Copenhagen, Denmark).

Cerebrospinal fluid (CSF) lactic acid was measured before antibiotic administration and at the conclusion of the study after the last blood flow measurement. Arterial lactate concentration was measured 
at baseline conditions and before $\mathrm{CBF}$ measurements. Lactate measurements were performed in a two-channel autoanalyzer (YSI model 2300 G/L; Yellow Springs Instrument Co., Yellow Springs, OH).

CBF was measured by the radionuclide-labeled microsphere technique as described by Heymann et al. (12). Microspheres, $15 \mu \mathrm{m}$ in diameter and labeled with $\left.\left[{ }^{153} \mathrm{Gd}\right],\left[{ }^{57} \mathrm{Co}\right],\left[{ }^{114 \mathrm{~m}} \mathrm{In}\right],{ }^{51} \mathrm{Cr}\right],\left[{ }^{113} \mathrm{Sn}\right],\left[{ }^{85} \mathrm{Sr}\right]$, $\left[{ }^{95} \mathrm{Nb}\right],\left[{ }^{54} \mathrm{Mn}\right]$, and $\left[{ }^{65} \mathrm{Zn}\right]$ were used. Approximately $1.5 \times 10^{5}$ microspheres were injected into the left ventricle over $15 \mathrm{~s}$ and flushed with $2.0 \mathrm{ml}$ of saline. The reference blood sample was withdrawn with a pump (Harvard Instruments, Cambridge, MA) from the femoral catheter, beginning $15 \mathrm{~s}$ before the injection and continuing for a total of 1.5 $\mathrm{min}$ at a rate of $2.5 \mathrm{ml} / \mathrm{min}$. After all blood flow and physiologic studies were completed, rabbits were killed by injection of a lethal dose of pentobarbital $(150 \mathrm{mg} / \mathrm{kg})$, and the brain was removed by dissection from the cranial vault. The brain was dissected into right and left hemispheres, and each tissue sample weighed in tared tubes.

Calculation of blood flow was determined by the formula: $C B F$ $=R B F \times C_{\mathrm{x}} / C_{\text {arterial }}$ where $R B F$ is the withdrawal rate of the reference arterial blood sample, $C_{\mathrm{X}}$ is counts per $100 \mathrm{~g}$ of brain tissues, and $C_{\text {arterial }}$ is total counts in the reference arterial blood sample.

Experimental studies. Rabbits were studied after two regimens of fluid administration. Group 1 (low fluid) rabbits received $0.9 \%$ saline at $50 \mathrm{ml} / \mathrm{kg}$ per $24 \mathrm{~h}$; Group 2 (high fluid) rabbits received $150 \mathrm{ml} / \mathrm{kg}$ per $24 \mathrm{~h}$. For $24 \mathrm{~h}$ before the study, rabbits had free access to food and water. On the day before measurements, rabbits had food and water withdrawn; from that time until the conclusion of the study, all supplemental fluids were administered intravenously. Fluid was given through a peripheral ear vein by continuous intravenous infusion through a flow-regulating in-line device (Dial-a-flow, Abbott Laboratories, Hospital Products Division, North Chicago, IL). The two fluid regimens were chosen because they approximated fluid recommendations for infants in various clinical states and were comparable to two fluid regimens utilized in a recent study of children with bacterial meningitis (9). After $16 \mathrm{~h}$ of infection, initial MABP, CBF, arterial blood gases, and arterial lactate concentrations were measured, then CSF was obtained for measurement of bacterial titer and lactate. Animals in both fluid groups were then given either $75 \mathrm{mg} / \mathrm{kg}$ i.v. ceftriaxone (treated) or an equivalent amount of vehicle (control), and repeat measurements were made after 4-6 $\mathrm{h}$.

Data are given as means \pm SD and were analyzed by paired Student's $t$ test for repeated measures in the same group and unpaired $t$ test for comparisons between groups. Values were considered significant when $P \geq 0.05$.

\section{Results}

Initial bacterial titers were comparable in low $(n=30)$ and high fluid $(n=22)$ rabbits after $16 \mathrm{~h}$ of infection (Table I). The rate of bacterial killing was also comparable in the two groups after antibiotic therapy, with bacterial titer reduction of $-0.75 \pm 0.41$ $\log _{10} \mathrm{CFU} / \mathrm{ml}$ per $\mathrm{h}$ for low fluid rabbits, compared with $-0.65 \pm 0.28$ for high fluid rabbits $(P=N S)$.

Table I. Bacteriologic Data in Low (Group I) and High Fluid (Group II) Rabbits before and after Antibiotic Therapy

\begin{tabular}{ccc}
\hline Group & Initial bacterial titer & Titer reduction \\
\hline $\log _{10} C F U / m l$ & $\log _{10} C F U /$ ml per $h$ \\
1 treated $(n=20)$ & $7.5 \pm 1.0$ & $-0.75 \pm 0.41$ \\
2 treated $(n=13)$ & $7.2 \pm 0.6$ & $-0.65 \pm 0.28$
\end{tabular}

Initial bacterial titer is at $16 \mathrm{~h}$ of infection; titer reduction represents the change per hour. 4-6 $\mathrm{h}$ after antibiotic treatment. $P$, NS.
Table II. Arterial Blood Gases at 16 h of Infection in Group 1 and Group 2 Rabbits

\begin{tabular}{ccccc}
\hline Group & $\mathrm{pH}$ & $\mathrm{PaCO}_{2}$ & $\mathrm{PaO}_{2}$ & Base excess \\
\hline & & $m m H g$ & $m m H g$ & $m m o l / l i t e r$ \\
$\begin{array}{c}\text { Group 1 } \\
(n=24)\end{array}$ & $7.26 \pm 0.09^{*}$ & $31.9 \pm 11.1$ & $88.6 \pm 18.9$ & $-11.9 \pm 4.1^{*}$ \\
$\begin{array}{c}\text { Group 2 } \\
(n=18)\end{array}$ & $7.32 \pm 0.07^{*}$ & $31.1 \pm 6.9$ & $85.1 \pm 13.6$ & $-9.3 \pm 3.6^{*}$ \\
\hline
\end{tabular}

${ }^{*} P<0.05$ (Student's $t$ test).

After $16 \mathrm{~h}$ of infection, arterial blood gases demonstrated a pattern of hypocarbia, normoxemia, and metabolic acidosis. Low fluid rabbits had significantly lower arterial $\mathrm{pH}$ (7.26 \pm 0.09 vs. $7.32 \pm 0.07 ; P<0.05)$ and greater base deficit $(-11.9 \pm 4.1$ vs. $-9.3 \pm 3.6 \mathrm{mmol} / \mathrm{l} ; P<0.05)$ than high fluid rabbits. Arterial oxygen and carbon dioxide concentrations were similar in the two groups (Table II). At the time of the second measurement, 4-6 $\mathrm{h}$ after administration of antibiotics or vehicle, there was progressive hyperventilation in all groups, but only low fluid rabbits had a worsening of the metabolic acidosis. After antibiotic treatment, low fluid animals had a significantly greater base deficit than high fluid rabbits $(-15.3 \pm 5.0$ vs. $-10.8 \pm 2.8 \mathrm{mmol} / \mathrm{l} ; P<0.01)$. A similar trend was observed in the difference in base deficit between low and high fluid controls, but this did not reach statistical significance $(-13.6 \pm 3.8$ vs. $-10.9 \pm 3.2 ; P>0.1$; Table III).

Arterial lactate concentration was somewhat higher in the low than in the high fluid group at $16 \mathrm{~h}$, although this difference was not statistically significant $(1.6 \pm 1.1$ vs. $1.1 \pm 0.5$ mmol/l; NS; Table IV). After treatment with antibiotics, arterial lactate was significantly higher in the low than in the high fluid group ( $2.9 \pm 1.6$ vs. $1.5 \pm 0.7 ; P<0.02)$, a finding that was not seen in low versus high fluid controls $(2.0 \pm 1.2$ vs. $1.8 \pm 0.6$; NS; Table V).

MABP was lower in low than in high fluid rabbits after $16 \mathrm{~h}$ of infection $(69.3 \pm 9.3$ vs. $84.3 \pm 9.4 \mathrm{mmHg} ; P<0.001$; Table IV). This difference persisted with the second measurement,

Table III. Arterial Blood Gases at 20-22 h of Infection, 4-6 h after Antibiotic or Vehicle Treatment of Group 1 and Group 2 Rabbits

\begin{tabular}{ccccc}
\hline Group & $\mathrm{pH}$ & $\mathrm{PaCO}_{2}$ & $\mathrm{PaO}_{2}$ & Base excess \\
\hline 1 & & $m m H g$ & $m m H g$ & $m m o l / l i t e r$ \\
$\begin{array}{c}\text { Treated } \\
(n=16) \\
\text { Control } \\
(n=8)\end{array}$ & $7.23 \pm 0.16$ & $29.9 \pm 13.6$ & $84.9 \pm 18.5$ & $-15.3 \pm 5.0^{*}$ \\
$2 \quad 7.29 \pm 0.09$ & $24.6 \pm 8.7$ & $93.5 \pm 19.0$ & $-13.6 \pm 3.8$ \\
$\begin{array}{c}\text { Treated } \\
(n=11)\end{array}$ & $7.32 \pm 0.09$ & $28.5 \pm 6.1$ & $77.6 \pm 15.4$ & $-10.8 \pm 2.8^{*}$ \\
$\begin{array}{c}\text { Control } \\
(n=7)\end{array}$ & $7.32 \pm 0.12$ & $28.7 \pm 7.4$ & $79.3 \pm 19.0$ & $-10.9 \pm 3.2$ \\
\hline
\end{tabular}

${ }^{*} P<0.01$ (Student's $t$ test). 
Table IV. Physiologic and Biochemical Measurements in Group 1 and Group 2 Rabbits at 16 h of Infection

\begin{tabular}{|c|c|c|c|c|}
\hline Group & MABP & $\mathrm{CBF}$ & CSF lactate & $\begin{array}{l}\text { Arterial } \\
\text { lactate }\end{array}$ \\
\hline & $m m H g$ & $\mathrm{ml} / \mathrm{min}$ per $100 \mathrm{~g}$ & $\mathrm{mmol} / \mathrm{liter}$ & $\mathrm{mmol} / \mathrm{liter}$ \\
\hline 1 & $69.3 \pm 9.3^{*}$ & $54.7 \pm 14.3^{\ddagger}$ & $6.9 \pm 2.8^{\S}$ & $1.6 \pm 1.1$ \\
\hline$n$ & 17 & 30 & 30 & 21 \\
\hline 2 & $84.3 \pm 9.4^{*}$ & $64.3 \pm 3.3^{\ddagger}$ & $5.3 \pm 2.7^{\S}$ & $1.1 \pm 0.5$ \\
\hline$n$ & 19 & 22 & 22 & 19 \\
\hline
\end{tabular}

* $P<0.01 ;{ }^{\ddagger .8} P<0.05$; all by unpaired Student's $t$ test. MABP, mean arterial blood pressure; CBF, cerebral blood flow; CSF, cerebrospinal fluid.

obtained after antibiotic therapy; however, some interesting differences were noted. Low fluid, antibiotic-treated rabbits had the largest drop in MABP, with nearly a $20 \%$ reduction compared with baseline, whereas low fluid control and high fluid, antibiotic-treated animals had a reduction of $6-8 \%$. As a result, low fluid, antibiotic-treated rabbits had significantly lower MABP than low fluid controls $(55.5 \pm 12.5$ vs. $65.2 \pm 3.6$; $P<0.05)$ and high fluid, antibiotic-treated rabbits $(55.5 \pm 12.5$ vs. $77.9 \pm 11.0 ; P<0.001)$. In the low fluid, antibiotic-treated rabbits, the extent of MABP reduction correlated significantly with the rate of bacterial killing (Fig. $1 ; r=0.61, P<0.05$ ), a finding that was not present in the high fluid, antibiotic-treated rabbits.

CBF was also lower in low than in high fluid rabbits after 16 h $(54.7 \pm 14.3$ vs. $64.3 \pm 13.3 \mathrm{ml} / \mathrm{min}$ per $100 \mathrm{~g} ; P<0.05$; Table IV). In parallel with the reduction in MABP, there was a marked reduction in CBF in the low fluid, antibiotic-treated rabbits 4-6 $\mathrm{h}$ after antibiotics were given, which did not occur in the high fluid, antibiotic-treated rabbits. Control rabbits in both low and high fluid groups did not have significant reduction of CBF at the time of the second measurement (Table V). Low fluid, antibiotic-treated rabbits demonstrated a reduction in CBF of $33 \%$ at the posttreatment measurement, which was

Table V. Physiologic and Biochemical Measurements in Group 1 and Group 2 Rabbits at 20-22 $h$ of Infection, 4-6 $h$ after Antibiotic or Vehicle Treatment

\begin{tabular}{|c|c|c|c|c|}
\hline Group & MABP & $\mathrm{CBF}$ & CSF lactate & $\begin{array}{l}\text { Arterial } \\
\text { lactate }\end{array}$ \\
\hline & $\mathrm{mmHg}$ & $\mathrm{ml} / \mathrm{min}$ per $100 \mathrm{~g}$ & mmol/liter & $\mathrm{mmol} /$ liter \\
\hline \multicolumn{5}{|l|}{1} \\
\hline Treated & $55.5 \pm 12.5^{* 1}$ & $36.5 \pm 25.1^{* \|}$ & $12.6 \pm 4.4^{\S}$ & $2.9 \pm 1.6^{\prime \prime}$ \\
\hline$n$ & 11 & 20 & 20 & 14 \\
\hline Control & $65.2 \pm 3.6^{\ddagger 1}$ & $54.0 \pm 12.5^{\prime \prime}$ & $10.9 \pm 3.6$ & $2.0 \pm 1.2$ \\
\hline$n$ & 6 & 10 & 10 & 7 \\
\hline \multicolumn{5}{|c|}{0} \\
\hline Treated & $77.9 \pm 11.0^{*}$ & $63.6 \pm 10.3^{*}$ & $9.6 \pm 2.5^{\S}$ & $1.5 \pm 0.7^{\prime \prime}$ \\
\hline$n$ & 12 & 13 & 13 & 12 \\
\hline Control & $77.6 \pm 7.1^{\ddagger}$ & $62.4 \pm 24.3$ & $9.8 \pm 4.5$ & $1.8 \pm 0.6$ \\
\hline$n$ & 7 & 9 & 9 & 7 \\
\hline
\end{tabular}

${ }^{*, \neq} P<0.001 ;{ }^{\S} P<0.01$; " $P<0.02$; ' $P<0.05$; all by unpaired Student's $t$ test. significantly lower than the baseline determination $(P<0.001$, paired $t$ test); than low fluid controls $(P<0.02$, unpaired $t$ test); and than high fluid, antibiotic-treated rabbits $(P<0.001$, unpaired $t$ test) (Table V). In low fluid rabbits, reduction of CBF appeared to occur through the effects of both reduction of MABP (Fig. 2, $r=0.62, P=0.04$ ) and rapid bacterial lysis (Fig. $3, r=0.44, P=0.02$ ).

Finally, low fluid rabbits had higher CSF lactic acid concentration than high fluid rabbits after $16 \mathrm{~h}(6.9 \pm 2.8$ vs. $5.3 \pm 2.7$ $\mathrm{mmol} / \mathrm{l} ; P<0.05$; Table IV). Although all groups had an increase in CSF lactate concentration in the 4-6 $\mathrm{h}$ after therapy, the highest CSF lactate was seen in the low fluid, antibiotictreated rabbits, where the level was significantly higher than in high fluid, antibiotic-treated rabbits (12.6 44.4 vs. $9.6 \pm 2.5 ; P$ $<0.01)$. Furthermore, CSF lactate concentration was inversely correlated with $\mathrm{CBF}$ in the low fluid, antibiotic-treated rabbits (Fig. 4, $r=0.63 ; P<0.005$ ) but not in the other groups.

\section{Discussion}

The factors leading to death or sequelae in bacterial meningitis are still incompletely understood. Pathophysiologic abnormalities in animal models of meningitis have been linked with hostderived factors, including cytokines (13), white blood cells (14), bacterial products $(10,15,16)$, and systemic variables (7). Clinical studies have reinforced the importance of some of these observations, with CSF IL- $1 \beta$ and tumor necrosis factor (17), CSF bacterial titer or bacterial antigen concentration (18), and reduced CPP $(5,6)$ or shock $(19)$ identified as factors that are associated with death or neurologic sequelae.

The present study evaluated the relationship among MABP, CBF, and CSF lactic acidosis in rabbits with experimental meningitis. Experimental conditions were varied by controlling the amount of fluid administration and by instituting antibiotic therapy. The rates of fluid administration were based on guidelines for fluid supplementation to infants and children with meningitis (20) and were comparable to those in a recent clinical study (9). The low fluid rabbits were given fluid supplementation, which resulted in intravascular volume depletion as judged by a decrease in MABP, whereas high fluid rabbits were supplemented at a rate that maintained normal MABP.

After $16 \mathrm{~h}$ of infection and after antibiotic therapy, we observed differences between low and high fluid-treated rabbits in two parameters that can potentially affect CBF: changes in blood carbon dioxide concentration and MABP. In the low fluid, antibiotic-treated group, $\mathrm{PaCO}_{2}$ was slightly lower than baseline; however, the high-fluid group hyperventilated to a similar degree, without a drop in CBF. Furthermore, the reduction of 2.0 Torr in $\mathrm{PaCO}_{2}$ in the low fluid, antibiotic-treated group is not sufficient to explain the $33 \%$ reduction in CBF. Other models of cerebral vasoreactivity have demonstrated $\sim 2 \%$ decrease in CBF for every 1.0-Torr decrease in $\mathrm{PaCO}_{2}$ (21), and the reduction in CBF we observed was in excess of what would have been caused by hyperventilation. The low fluid group also had a marked reduction in MABP relative to the high fluid group. Since previous studies in the same model have documented a loss of cerebrovascular autoregulation (7) that makes $\mathrm{CBF}$ pressure passive to MABP, the reduction in CBF was not unexpected. However, it extends the previous observation from a situation in which CBF changed in response to an acute manipulation of MABP to one that may occur in the clinical setting. 


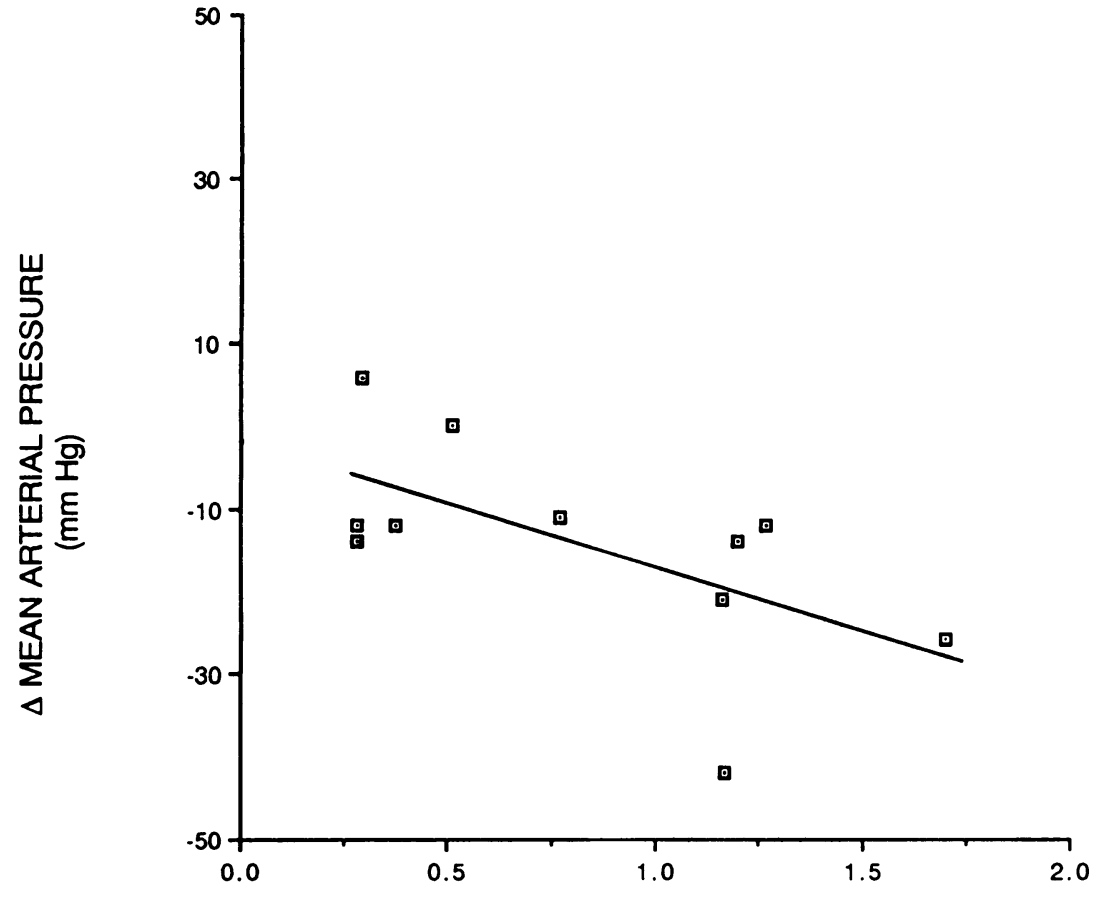

BACTERIAL TITER REDUCTION $(\log c f u / h)$
Figure 1. Change in MABP as a function of change in CSF bacterial titer 4-6 $\mathrm{h}$ after antibiotic administration in low fluid rabbits. MABP reduction was significantly associated with rate of bacterial titer reduction. $(y=-1.75-15.4 x, r=0.61$, $P<0.05)$.
The consequences of bacterial lysis on CBF were more difficult to anticipate. Vasodilatation of the systemic vasculature is well known to occur in animal models of sepsis after release of endotoxin by antibiotic therapy (22). That this may also occur in the central nervous system in pneumococcal meningitis is suggested by a recent study by Pfister et al. (23), which documented an increase in CBF occurring within the first few hours of intracisternal inoculation of either live pneumococci or pneumococcal cell wall fragments in the rat. While some of our high fluid rabbits showed a mild increase of CBF after antibi-

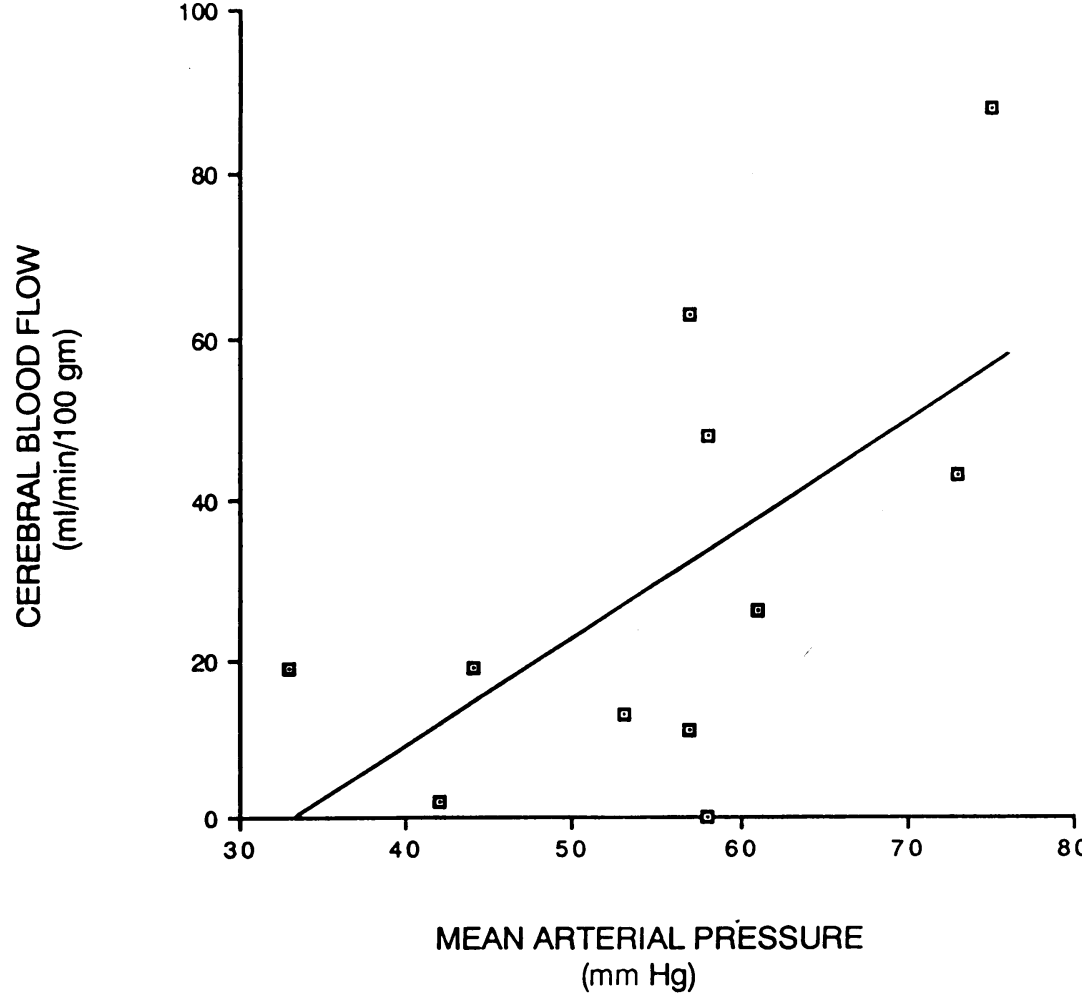

Figure 2. Relationship between $\mathrm{CBF}$ and MABP 4-6 $\mathrm{h}$ after antibiotic treatment of low fluid rabbits. CBF shows a direct relationship to MABP. ( $y$ $=-45.3+1.36 x, r=0.62, P=0.04)$. 


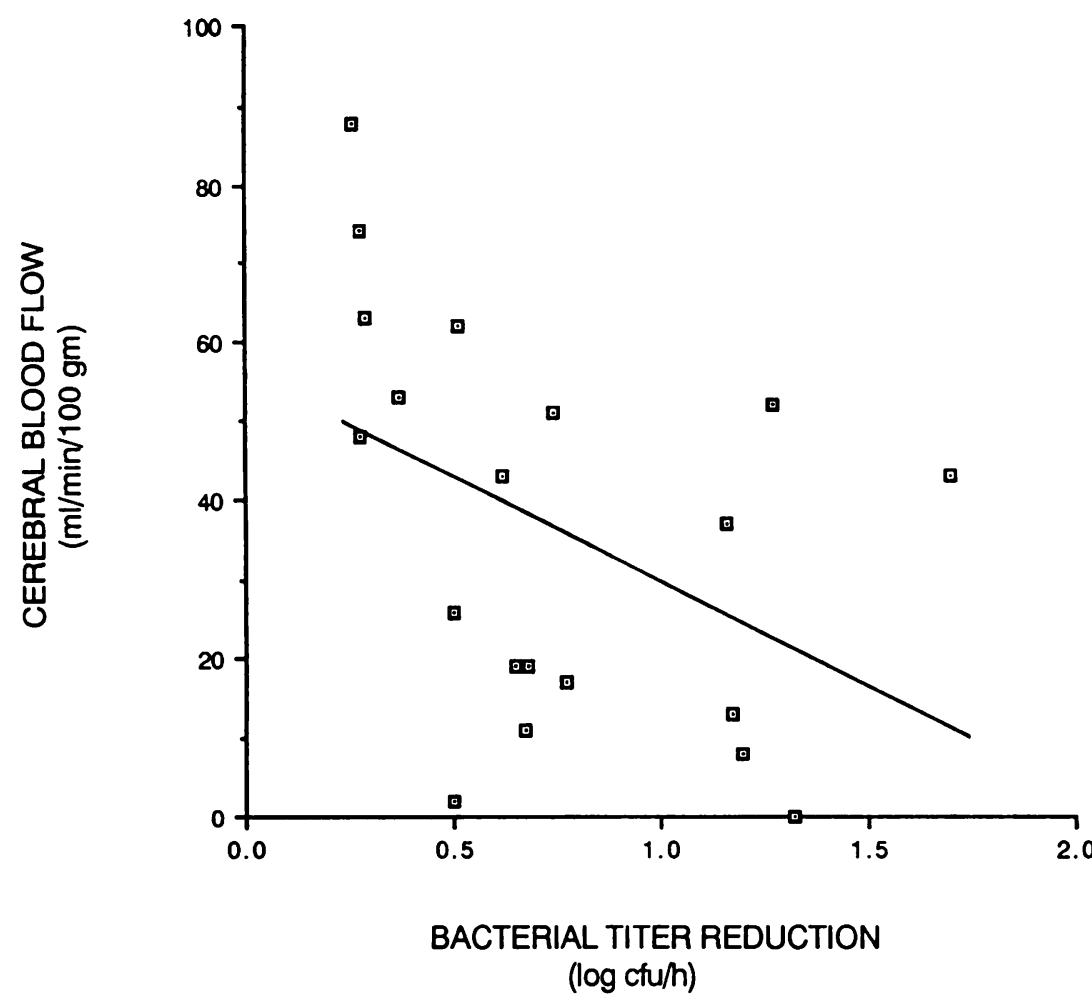

Figure 3. Relationship between $\mathrm{CBF}$ and rate of bacterial titer reduction 4-6 $\mathrm{h}$ after antibiotic treatment of low fluid rabbits. CBF shows a significant inverse relationship to the rate of bacterial killing. ( $y=56.1-26.3 x, r=0.44, P=0.02)$. otic therapy, the most dramatic and consistent changes occurred in low fluid animals given antibiotics, in which MABP and CBF decreased sharply. The further reduction of CBF in response to antibiotic-induced hypotension lends additional support to the effect of systemic factors on CBF in this disease.
A number of studies of children with meningitis have identified CSF bacterial titer (18) or CSF bacterial antigen concentration (24) as factors that have been associated with poor outcome, although the mechanism by which this occurs is not known. In the present study, the initial titers and the rate of

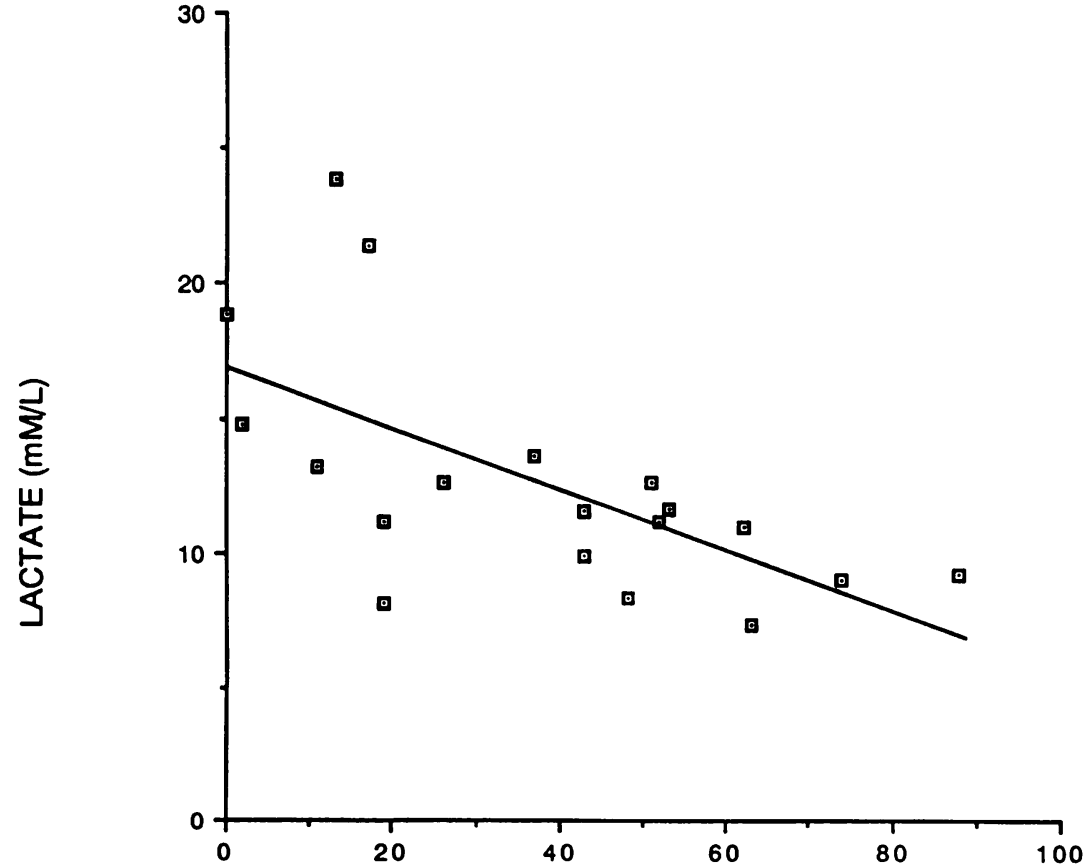

CEREBRAL BLOOD FLOW

$(\mathrm{ml} / \mathrm{min} / 100 \mathrm{gm})$
Figure 4. Relationship between CSF lactate and CBF after 20-22 h of infection, 4-6 h after antibiotic treatment of low fluid rabbits. There is a significant inverse correlation of lactate to CBF. ( $y$ $=16.85-0.11 x, r=0.63, P<0.005$ ). 
titer reduction were comparable among the groups. However, in the low fluid, antibiotic-treated rabbits there was a marked reduction in MABP and $\mathrm{CBF}$ after antibiotic administration, and there were significant correlations between the rate of bacterial killing and changes in both MABP and CBF. It seems likely that these rabbits were more sensitive to the systemic consequences of bacterial lysis because of compromised volume status.

In addition to the reduction in CBF, we also observed a significant increase in CSF lactate concentration, a marker for anaerobic metabolism (25). The source of CSF lactate in meningitis is still unknown and has been variously ascribed to anaerobic glucose metabolism by bacteria, by phagocytosis of bacteria by white blood cells $(26,27)$, or by ischemic brain $(28)$. The present study supports the concepts that cerebral ischemia plays a part in the development of elevated CSF lactate in meningitis and that there may be other stimuli that induce anaerobic cerebral metabolism as well. After $16 \mathrm{~h}$ of infection, CSF lactate was higher in the low fluid group; this pattern intensified after antibiotic treatment, which further lowered CBF. The link between ischemia and elevated CSF lactate is further supported by the strong correlation between the magnitude of $\mathrm{CBF}$ reduction and elevation of CSF lactate in the low fluid, antibiotic-treated group. However, it is also clear that reduction in total brain blood flow alone is not sufficient to completely explain CSF lactic acidosis in this disease. The control groups and the high fluid, antibiotic-treated group had increased CSF lactate at $16 \mathrm{~h}$, which increased progressively after 4-6 h in spite of CBF that did not change significantly over the period of observation. Possible explanations for this would include focal areas of ischemia that have been documented to occur in meningitis (29) but that would not be detected by measurement of total organ blood flow or humoral factors that would work in concert with ischemia to induce anaerobic metabolism. In other tissues, anaerobic glycolysis has been shown to be accelerated by humoral factors, including cytokines, resulting in increased glucose utilization and lactate production (30). This may be particularly relevant to the central nervous system in meningitis, where elevated cytokine levels have been measured in CSF and been found to be associated with poor outcome $(13,17)$.

The present data reinforce the clinical observations regarding potential contribution of systemic factors to central nervous system compromise in meningitis. Goitein and Tamir (5) described the consequences of reduced CPP in children with intracranial infections and reported that $\mathrm{CPP}$ below $30 \mathrm{mmHg}$ was uniformly associated with death or poor neurologic function in survivors. In that study, the degree of intracranial hypertension alone was not a negative prognostic factor if it was associated with a corresponding elevation in systemic MABP to maintain CPP. Other retrospective data have identified shock at the time of admission as a factor associated with poor outcome (19). More recently, Odio et al. (6), in a carefully done prospective study, reported that CPP $<40 \mathrm{mmHg}$ was almost uniformly associated with long-term neurologic residua.

Additional evidence pointing to the importance of systemic factors comes from studies that have documented elevated serum arginine vasopressin (AVP) concentration in patients with meningitis (31). First described in 1964 in a child with chronic ventriculitis and basilar meningitis due to Staphyloccocus aureus (32), elevated serum AVP was identified in prospective studies of children with meningitis as a factor associated with poor neurologic outcome (24). Because of the concern that elevated serum AVP is due to the syndrome of inappropriate secretion of antidiuretic hormone (SIADH), it is recommended that these patients be fluid restricted until serum electrolytes have normalized (8). However, it is possible that elevated serum AVP may also be an appropriate physiologic response to intravascular volume depletion in some children with meningitis. A recent study by Powell et al. (9) has addressed this point. Serum AVP was measured on admission and after $24 \mathrm{~h}$ of therapy in 13 children with meningitis. The patients were prospectively randomized to one of two regimens of fluid administration: one treated with conventional fluid restriction $(60 \mathrm{ml} / \mathrm{kg}$ per $24 \mathrm{~h})$, the other with maintenance plus deficit replacement ( $150 \mathrm{ml} / \mathrm{kg}$ per $24 \mathrm{~h}$ ). Serum AVP was elevated in both groups on admission, but at $24 \mathrm{~h}$ remained significantly higher in the group treated with fluid restriction than in the group given liberalized fluids, suggesting that the elevated serum AVP was an indicator of intravascular volume depletion rather than a manifestation of SIADH.

The present study may have important clinical implications in light of these findings. The poor outcome of patients with increased serum AVP is generally assumed to be due to more generalized brain injury or dysfunction, as evidenced by the presence of SIADH, or to the complications of cerebral edema. However, if elevated serum AVP concentration in some patients is an appropriate response to intravascular volume depletion rather than the result of hypothalamic-pituitary axis dysfunction, then ongoing fluid restriction may be harmful. It is important to note that the most dramatic changes in blood pressure, CBF, and CSF lactic acidosis occurred in the low fluid group after administration of antibiotics and that in the high fluid group these changes did not occur or were somewhat attenuated. In our study, the low fluid group may be considered analogous to the patient who presents with moderate intravascular depletion and is maintained on restricted fluids. In this situation, moderate dehydration and continued fluid restriction can substantially contribute to systemic hypotension after administration of antibiotics, which, in turn, may lead to decreased cerebral perfusion and progressive cerebral anaerobic metabolism. We conclude that systemic factors may contribute to abnormalities in the central nervous system during meningitis and that ongoing fluid restriction may lead to cerebral ischemia, particularly after institution of antibiotic therapy.

\section{Acknowledgments}

Technical assistance was provided by Michael A. Fournier and Stephen L. Kennedy.

This work was supported in part by National Institutes of Health grant NS-27310.

\section{References}

1. Smith, A. L. 1983. Pathogenesis of Haemophilus influenzae type b meningitis. In Experimental Bacterial and Parasitic Infections. G. Deusch and T. Wadstrom, editors. Elsevier Science Publishing, New York. 295-301.

2. Täuber, M. G., M. Burroughs, U. M. Niemöller, H. Kuster, U. Borschberg, and E. Tuomanen. 1991. Differences of pathophysiology in experimental meningitis caused by three strains of Streptococcus pneumoniae. J. Infect. Dis. 163: 806-811.

3. Paulson, O. B., P. Broderson, E. L. Hansen, and H. S. Kristensen. 1974. Regional cerebral blood flow, cerebral metabolic rate of oxygen and cerebrospinal 
fluid acid-base variables in patients with acute meningitis and acute encephalitis. Acta Med. Scand. 196:191-198.

4. Ashwal, S., W. Stringer, L. Tomasi, S. Schneider, J. Thompson, and R. Perkin. 1990. Cerebral blood flow and carbon dioxide reactivity in children with bacterial meningitis. J. Pediatr. 117:523-530.

5. Goitein, K. J., and I. Tamir. 1983. Cerebral perfusion pressure in central nervous system infections of infancy and childhood. J. Pediatr. 103:40-43.

6. Odio, C. M., I. Faingezicht, M. Paris, M. Nassar, A. Baltodano, J. Rogers, X. Saez-LLorens, K. D. Olsen, and G. H. McCracken, Jr. 1991. The beneficial effects of early dexamethasone administration in infants and children with bacterial meningitis. N. Engl. J. Med. 324:1525-1531.

7. Tureen, J. H., R. J. Dworkin, S. L. Kennedy, M. Sachdeva, and M. A Sande. 1990. Loss of cerebrovascular autoregulation in experimental meningitis in rabbits. J. Clin. Invest. 85:577-581.

8. Feigin, R. D. 1987. Bacterial meningitis beyond the newborn period. In Textbook of Pediatric Infectious Diseases. R. D. Feigin and J. D. Cherry, editors. W. B. Saunders, Philadelphia. 439-465.

9. Powell, K. R., L. I. Sugarman, A. E. Eskenazi, K. A. Woodlin, M. A. Kays, K. L. McCormick, M. E. Miller, and C. D. Sladek. 1990. Normalization of plasma arginine vasopressin concentrations when children with meningitis are given maintenance plus replacement fluid therapy. J. Pediatr. 117:515-522.

10. Täuber, M. G., A. M. Shibl, C. J. Hackbarth, J. W. Larrick, and M. A. Sande. 1987. Antibiotic therapy, endotoxin concentrations in spinal fluid, and brain edema in experimental Escherechia coli meningitis. J. Infect. Dis. 156:456462.

11. Dacey, R. G., and M. A. Sande. 1974. Effect of probenecid on cerebrospinal fluid concentrations of penicillin and cephalosporin derivatives. Antimicrob. Agents Chemother. 6:437-441.

12. Heymann, M. A., B. D. Payne, J. I. E. Hoffman, and A. M. Rudolph. 1977. Blood flow measurements with radionuclide-labeled particles. Prog. Cardiovasc. Dis. 20:55-70.

13. Mustafa, M. M., O. Ramilo, K. D. Olsen, P. S. Franklin, E. J. Hansen, B. Buetler, and G. H. McCracken, Jr. 1989. Tumor necrosis factor in mediating experimental Haemophilus influenzae type B meningitis. J. Clin. Invest. 84:1253-1259.

14. Täuber, M. G., U. Borschberg, and M. A. Sande. 1988. Influence of granulocytes on brain edema, intracranial pressure, and cerebrospinal fluid concentrations of lactate and protein in experimental meningitis. J. Infect. Dis. 157:456-464.

15. Tuomanen, E. I., A. Tomasz, B. Hengstler, and O. Zak. 1985. The relative role of bacterial cell wall and capsule in the induction of inflammation in pneumococcal meningitis. J. Infect. Dis. 151:535-540.

16. Tuomanen, E., H. Liu, B. Hengstler, O. Zak, and A. Tomasz. 1985. The induction of meningeal inflammation by components of the pneumococcal cell wall. J. Infect. Dis. 152:859-868.

17. Mustafa, M. M., M. H. Lebel, O. Ramilo, K. D. Olsen, J. S. Reisch, B.
Buetler, and G. H. McCracken, Jr. 1989. Correlation of interleukin-1-beta and cachectin concentrations in cerebrospinal fluid and outcome from bacterial meningitis. J. Pediatr. 115:208-213.

18. Feldman, W. E., C. M. Ginsburg G. H. McCracken, Jr., D. Allen, P. Ahmann, J. Graham, and L. Graham. 1982. Relation of concentrations of Haemophilus influenzae type $\mathrm{b}$ in cerebrospinal fluid to late sequelae of patients with meningitis. J. Pediatr. 100:209-212.

19. Herson, V. C., and J. K. Todd. 1977. Prediction of morbidity in Haemophilus influenzae meningitis. Pediatrics. 59:35-39.

20. Greene, M. G., editor. 1991. The Harriet Lane Handbook. A Manual for Pediatric House Officers. 12th ed. Mosby-Year Book, Inc., St. Louis, MO. p. 271.

21. Grubb, R. L., Jr., M. E. Raichle, J. O. Eichling, and M. M. Ter-Pogossian. 1974. The effects of changes in $\mathrm{PaCO}_{2}$ on cerebral blood volume, blood flow, and vascular mean transit time. Stroke. 5:630-639.

22. Robinson, J. A., M. L. Klonnycky, and H. S. Loeb. 1975. Endotoxin, prekallekrein, complement, and systemic vascular resistance: sequential measurement in man. Am. J. Med. 59:61-67.

23. Pfister, H.-W., U. Koedel, R. L. Haberl, U. Dinargl, W. Feiden, G. Ruckdeschel, and K. M. Einhäupl. 1990. Microvascular changes during the early phase of experimental bacterial meningitis. J. Cereb. Blood Flow Metab. 10:914-922.

24. Feigin, R. D., B. W. Stechenberg, M. J. Chang, L. M. Dunkle, M. L. Wong, H. Palkes, P. R. Dodge, and H. Davis. 1976. Prospective evaluation of treatment of Haemophilus influenzae meningitis. J. Pediatr. 88:542-548.

25. Brook, I., K. S. Bricknell, G. D. Overturf, and S. M. Feingold. 1978. Measurement of lactic acid in cerebrospinal fluid of patients with infections of the central nervous system. J. Infect. Dis. 137:384-390.

26. Petersdorf, R. G., D. M. Swarner, and M. Garcia. 1961. Studies of the pathogenesis of meningitis. III. Relationship of phagocytosis to the fall in cerebrospinal fluid sugar in experimental meningitis. J. Lab. Clin. Med. 61:745-754.

27. Andersen, N. E. O., J. Gyring, A. J. Hansen, H. Larsen, and B. K. Siesjo 1989. Brain acidosis in experimental pneumococcal meningitis. J. Cereb. Blood Flow Metab. 9:381-387.

28. Prokop, L. D., and R. A. Fishman. 1966. Pathophysiology of the cerebrospinal fluid changes in experimental pneumococcal meningitis. Trans. Am. Neurol. Assoc. 91:126-131.

29. Cairns, H., and D. S. Russell. 1946. Cerebral arteritis and phlebitis in pneumococcal meningitis. J. Pathol. Bacteriol. 58:649-665.

30. Tredgett, E. E., Y. M. Yu, S. Zhong, R. Burini, S. Okusawa, J. A. Gelfand C. A. Dinarello, V. R. Young, and J. F. Burke. 1988. Role of interleukin 1 and tumor necrosis factor on energy metabolism in rabbits. Am. J. Physiol. 255:E760-E768.

31. Kaplan, S. L. and R. D. Feigin. 1978. The syndrome of inappropriate secretion of antidiuretic hormone in children with bacterial meningitis. $\mathrm{J}$. Pediatr. 92:758-761.

32. Mangos, J. A., and C. C. Lobeck. 1964. Studies of sustained hyponatremia due to central nervous system infection. Pediatrics. 34:503-510. 